\title{
Trends in Roll-Your-Own Smoking: Findings from the ITC Four-Country Survey (2002-2008)
}

\author{
David Young, ${ }^{1}$ Hua-Hie Yong, ${ }^{1}$ Ron Borland, ${ }^{1}$ Lion Shahab, ${ }^{2}$ David Hammond, ${ }^{3}$ \\ K. Michael Cummings, ${ }^{4}$ and Nick Wilson ${ }^{5}$ \\ ${ }^{1}$ Tobacco Control Unit, Cancer Council Victoria, 100 Drummond Street Carlton, VIC 3053, Australia \\ ${ }^{2}$ Cancer Research UK, Health Behaviour Unit, Department of Epidemiology and Public Health, University College, \\ London WC1E6XA, UK \\ ${ }^{3}$ Department of Psychology, University of Waterloo, 200 University Avenue West, Waterloo, ON, Canada N2L 3G1 \\ ${ }^{4}$ Department of Health Behavior, Roswell Park Cancer Institute, Elm and Carlton Streets, Buffalo, NY 14263, USA \\ ${ }^{5}$ Department of Public Health, University of Otago Wellington, P.O. Box 7343, Wellington South 6242, New Zealand
}

Correspondence should be addressed to David Young, david.young@cancervic.org.au

Received 10 November 2011; Revised 5 March 2012; Accepted 6 March 2012

Academic Editor: Lorraine Greaves

Copyright ( 2012 David Young et al. This is an open access article distributed under the Creative Commons Attribution License, which permits unrestricted use, distribution, and reproduction in any medium, provided the original work is properly cited.

\begin{abstract}
Objective. To establish the trends in prevalence, and correlates, of roll-your-own (RYO) use in Canada, USA, UK and Australia, 2002-2008. Methods. Participants were 19,456 cigarette smokers interviewed during the longitudinal International Tobacco Control (ITC) Four-Country Survey in Canada, USA, UK, and Australia. Results. "Predominant" RYO use (i.e., >50\% of cigarettes smoked) increased significantly in the UK and USA as a proportion of all cigarette use (both $P<.001$ ) and in all countries as a proportion of any RYO use (all $P<.010$ ). Younger, financially stressed smokers are disproportionately contributing to "some" use (i.e., $\leq 50 \%$ of cigarettes smoked). Relative cost was the major reason given for using RYO, and predominant RYO use is consistently and significantly associated with low income. Conclusions. RYO market trends reflect the price advantages accruing to RYO (a product of favourable taxation regimes in some jurisdictions reinforced by the enhanced control over the amount of tobacco used), especially following the impact of the Global Financial Crisis; the availability of competing low-cost alternatives to RYO; accessibility of duty-free RYO tobacco; and tobacco industry niche marketing strategies. If policy makers want to ensure that the RYO option does not inhibit the fight to end the tobacco epidemic, especially amongst the disadvantaged, they need to reduce the price advantage, target additional health messages at (young) RYO users, and challenge niche marketing of RYO by the industry.
\end{abstract}

\section{Introduction}

This paper explores patterns of roll-your-own (RYO) use in four developed countries (USA, UK, Canada, and Australia). RYO cigarettes are an important component of the tobacco market in many countries, with wide variation in use. For example, a majority of smokers use RYO at least some of the time in New Zealand (NZ) (53\%) [1] and Thailand (58\%) [2], compared with $7 \%$ in the USA [3]. In 2002, the other three countries in the study reported here had intermediate prevalence with $28 \%$ in UK, $24 \%$ in Australia, and $12 \%$ in Canada [3].

The 2002 cross-sectional study [3] found that RYO use was associated with lower income, male sex, greater nicotine addiction, lower intention to quit, and greater likelihood to believe RYO tobacco is less harmful to health. In NZ [1] there was a strong interaction between age and socioeconomic status (SES), with use amongst younger smokers increasing more as SES declined, relative to older smokers, suggesting uptake of RYO is a strategy of younger, poorer smokers. SES is also important in middle income countries; in Malaysia and Thailand RYO smoking was associated with low income, low education, and being unemployed [2].

The primary driver for RYO is the price differential between factory-made (FM) and RYO cigarettes, due in part to differences in how these products are taxed $[1,2]$. Not only is RYO tobacco subject to lower taxation in many countries, but 
it is also much easier to control the amount of tobacco used by rolling thinner cigarettes [4]. Evidence from previous ITC Project RYO studies [3,5] also indicates that RYO smokers have a disproportionate tendency to believe RYO tobacco is less harmful and $20-30 \%$ cite "it (RYO) is not as bad for your health" as a reason for smoking RYO $[1,6]$, even though research suggests that RYO cigarettes are at least as harmful, and if anything more harmful, than FM cigarettes [7-10].

It has been reported elsewhere [11] that the prevalence of RYO use is increasing in some countries. There is evidence that use has increased in the UK [12], and it has been argued that this is due to both the tax differential between RYO and FM in the UK and easy access to duty-free rolling tobacco in continental Europe [13]. To the extent that its cheaper cost is a prime motive, the Global Financial Crisis (GFC) could be driving any increases in RYO use identified in the study being reported here, especially in the USA and UK, where there was evidence of deteriorating economic conditions since 2005 [14-16] and where the impact has been particularly severe and long lasting.

In addition, industry documents reveal that the UK has been subject to a systematic campaign to change the image of RYO from a low-cost, down-market, product to a "cool," "natural" choice [3]. On-pack advertising in Australia also reflects this strategy, and there is some anecdotal evidence that the myth that RYO tobacco is more "natural" (and by implication "safer") is widespread in that country [17].

On the other hand, in Canada, the ease of access to cheaper contraband cigarettes [18] and the prevalence of discounting FM cigarettes are factors that would make the use of RYO for economic reasons less likely.

In an effort to extend the findings of our earlier work [3] based on data from the first wave of the ITC Four-Country Study, this study used six additional waves of data, a total of 7 waves covering the period from late 2002 to the end of 2008 , specifically:

(1) to examine trends in RYO use relative to FM cigarette smoking,

(2) to determine if RYO prevalence has been rising in the UK and the USA, relative to Canada, given the different circumstances applying in those jurisdictions,

(3) to examine whether RYO use was greater and/or has been increasing disproportionately among young, financially disadvantaged smokers, given the results of the NZ study,

(4) to examine the prevalence of the reason that "RYO is less harmful" for smoking RYO and to determine if the importance of this reason has changed relative to other reasons for using RYO.

\section{Methods}

2.1. The ITC Project. The ITC Project is a multicountry study on tobacco use and tobacco control policy evaluation. Detailed descriptions of the project's conceptual framework and methods have been published elsewhere [19-21].
Participants were adult (18 years of age and older) cigarette smokers (who currently smoked at least once a month) from Canada, USA, UK, and Australia. The survey was designed as a longitudinal study to simultaneously evaluate several leading tobacco control policies subject to implementation over the time period of the study. The survey was conducted annually at around the same time of the year as much as possible with any variation in timing mainly for the purpose of enabling pre/posttests of policy changes (e.g., banning the term "lights" in the UK, labeling changes in Australia and Canada) [22]. The total number of participants was 19,456 , a sample of approximately 2000 respondents per country per year (2002-2008), a retention rate of around $70 \%$ each year with $30 \%$ replenishment. Although ex-smokers are retained in the cohort, they are not included in the analyses reported here.

The survey field work was conducted using computerassisted telephone interviews (CATIs). The survey was conducted in English or in French if desired in the Francophone areas of Canada. Strict protocols were developed and implemented to ensure equivalence of methods.

The study protocol was cleared for ethics by the Institutional Review Boards or Research Ethics Boards in each of the countries: the University of Waterloo (Canada), Roswell Park Cancer Institute (USA), University of Illinois-Chicago (USA), University of Strathclyde (UK), and The Cancer Council Victoria (Australia).

\subsection{Measures}

2.2.1. RYO Use. All respondents were asked if they smoked "FM cigarettes only," "mainly FM," "FM and RYO similar," "mainly RYO," or "only RYO." Based on these responses, RYO use was categorized in three ways: "Sometime RYO use" (mainly FM, FM \& RYO similar); "Predominant RYO use" (mainly or only RYO, i.e., $>50 \%$ of cigarettes smoked); and "Any RYO" use (i.e., either "sometime" or "predominant").

2.2.2. Sociodemographic Measures. Age (corrected for time in the sample), sex, income and education were measured the same way as previously reported $[3,17,21]$. From Wave 4 onwards smokers were also asked if they had been experiencing financial stress in the last 12 months ("unable to pay important bills on time"; yes/no), a single-item measure that has been used successfully in previous studies [23].

2.2.3. Smoking Behaviors. They were heaviness of Smoking Index [24] (a combination of number of cigarettes per day with time to first cigarette), intention to quit (yes/no), and number of friends who smoke (out of a total of 5 closest friends).

2.2.4. Reasons for Smoking RYO. This was a multiple response variable and has only been asked from Wave 5 onwards. Respondents were asked to identify up to four reasons from a list: because they are cheaper; because of the taste; because they help you reduce the amount smoked; because they are not as bad for your health. 
TABle 1: Prevalence (\%) of exclusive factory-made (FM) use, sometime (“Some”) RYO use, and predominant ("Pred”) RYO use by country and across waves (weighted data).

\begin{tabular}{lccccccccccccc}
\hline \multirow{2}{*}{ Wave (year) } & \multicolumn{3}{c}{ Canada } & \multicolumn{4}{c}{ United States } & \multicolumn{3}{c}{ United Kingdom } & \multicolumn{3}{c}{ Australia } \\
& FM & Some RYO & Pred RYO & FM & Some RYO & Pred RYO & FM & Some RYO & Pred RYO & FM & Some RYO Pred RYO \\
\hline $1(2002)$ & 81.6 & 6.2 & 12.2 & 92.9 & 5.1 & 2.1 & 69.6 & 8.8 & 21.6 & 73.1 & 12.6 & 14.3 \\
$2(2003)$ & 83.0 & 5.9 & 11.5 & 93.4 & 4.4 & 2.3 & 68.2 & 7.4 & 24.4 & 75.2 & 9.9 & 14.9 \\
$3(2004)$ & 83.7 & 6.1 & 10.2 & 93.1 & 4.7 & 2.2 & 68.7 & 6.8 & 24.5 & 76.4 & 9.3 & 14.3 \\
$4(2005)$ & 83.9 & 5.1 & 11.0 & 91.2 & 5.9 & 2.8 & 67.6 & 6.2 & 26.2 & 77.5 & 7.8 & 14.7 \\
$5(2006)$ & 85.0 & 4.5 & 10.5 & 90.2 & 6.4 & 3.3 & 63.2 & 7.4 & 29.4 & 74.9 & 9.0 & 16.1 \\
$6(2007)$ & 87.3 & 4.2 & 8.6 & 90.3 & 4.5 & 5.2 & 62.3 & 6.1 & 31.5 & 77.3 & 7.7 & 15.0 \\
$7(2008)$ & 87.9 & 3.3 & 8.8 & 89.1 & 5.2 & 5.7 & 62.0 & 6.6 & 31.5 & 78.2 & 6.4 & 15.4 \\
\hline$P$ value for trend & .001 & .006 & .080 & .078 & .677 & $<.001$ & $<.001$ & .039 & $<.001$ & .055 & $<.001$ & .131 \\
\hline
\end{tabular}

2.3. Weighting and Statistical Analyses. All analyses were carried out using version 18.0.1 of the PASW (previously SPSS) statistical package. Weights have been designed to make the data representative of smokers in each of the four countries. There was no between-countries weighting. Weighted data are reported for the univariate and bivariate analyses, including self-reported prevalence. We used general estimating equations (GEEs) for multivariate analysis, since this technique allows for correlated data sets across the waves.

\section{Results}

3.1. Trends in the Prevalence of RYO Use. The prevalence of FM and RYO use by country across waves are presented in Table 1. The proportion of smokers using any RYO was highest in the UK and lowest in the USA in every wave. The prevalence of any RYO use relative to FM increased significantly in the UK $(P<.001)$, while there was a nonsignificant increase in the USA $(P=.078)$. It decreased significantly in Canada $(P=.001)$ and marginally in Australia (albeit, not significantly; $P=.055$ ). These overall trends were supported by within-subjects data (i.e., data from those who were present across all 7 waves); there was more switching from exclusive FM to any RYO use in the UK, and the USA, and the reverse applied in Canada and Australia.

Over the study period, predominant use rose significantly in the UK and the USA, while there was a near-significant decline in Canada and Australia was flat. The prevalence of predominant RYO use as a proportion of any RYO use increased in all four countries (all $P<.010$ ).

3.2. Correlates of Predominant RYO Use. Because of the increasing relative and/or absolute prevalence of predominant use we decided to focus on predominant RYO use as a proportion of all cigarette use. The GEE analysis revealed that country was the variable most strongly associated with predominant use of RYO compared with all other forms of smoking $(P<.001)$ (data not shown). There were also main effects of sex, income, heaviness of smoking, age, intention to quit (all $P<.001$ ), and number of smokers in their social network $(P=.002)$. We also included the "financial stress" in the four Waves where it was measured, but it was not significant. We found significant interactions of country by sex, country by wave, country by age (all $P<.001$ ), and country by income $(P=.007)$. Because of the strong bycountry interactions, we carried out separate GEE analyses for each country (see Table 2).

The common correlates of predominant RYO use (compared with all other cigarette use) were (low) income and (older) age. However the age effect was weaker in Canada. Similarly, males reported more RYO use, but this trend was also smaller, and nonsignificant, in Canada. In the UK and Australia predominant users were significantly less likely to intend to quit than were other smokers. There was a similar trend in Canada, but not in the USA. In addition, predominant RYO users in Canada and Australia tended to be heavier smokers.

3.3. Comparison of Sometime Users with Predominant Users of RYO. A GEE analysis was carried out comparing sometime users with predominant users of RYO. The significant correlates of sometime use (rather than predominant use), using the seven waves of data were country, age, income, sex, (all $P<.001)$, and wave $(P=.019)$. A greater proportion of RYO smokers were sometime users in the USA $(\mathrm{OR}=3.14$; $P<.001)$ compared with the UK $(\mathrm{OR}=.57 ; P<.001)$, and compared with Wave 1 , the relative prevalence of sometime use showed significant falls in Waves Four $(\mathrm{OR}=.90 ; P=$ $.047)$, Six $(\mathrm{OR}=.86 ; P=.034)$ and Seven $(\mathrm{OR}=.75 ; P<$ .001). Compared with predominant RYO users, sometime users were more likely to have higher incomes $(\mathrm{OR}=1.27$; $P<.001)$ and, importantly, sometime users were younger than predominant RYO users, and the difference increased with age group $(18-24=$ reference, $25-39: \mathrm{OR}=.58 ; P<$ $.001,40-54: \mathrm{OR}=.39 ; P<.001,55+\mathrm{OR}=.29 ; P<.001)$. Compared with predominant users, they were also less likely to be male $(\mathrm{OR}=.79 ; P<.001)$ and were marginally more likely to intend to quit $(\mathrm{OR}=1.08 ; P=.054)$.

Given the large by-country interactions, results are presented separately by country. Sometime RYO smokers were younger than predominant RYO smokers in all four countries. In addition, Canadian sometime users smoked less, US sometime users were significantly less likely to be in the low income bracket, and UK and Australian sometime users were significantly less likely to be male. In addition, there was 
TABLE 2: Multivariate results of GEE analyses by country for predominant use of RYO compared to all other smoking patterns (factory-made cigarettes or "some" RYO).

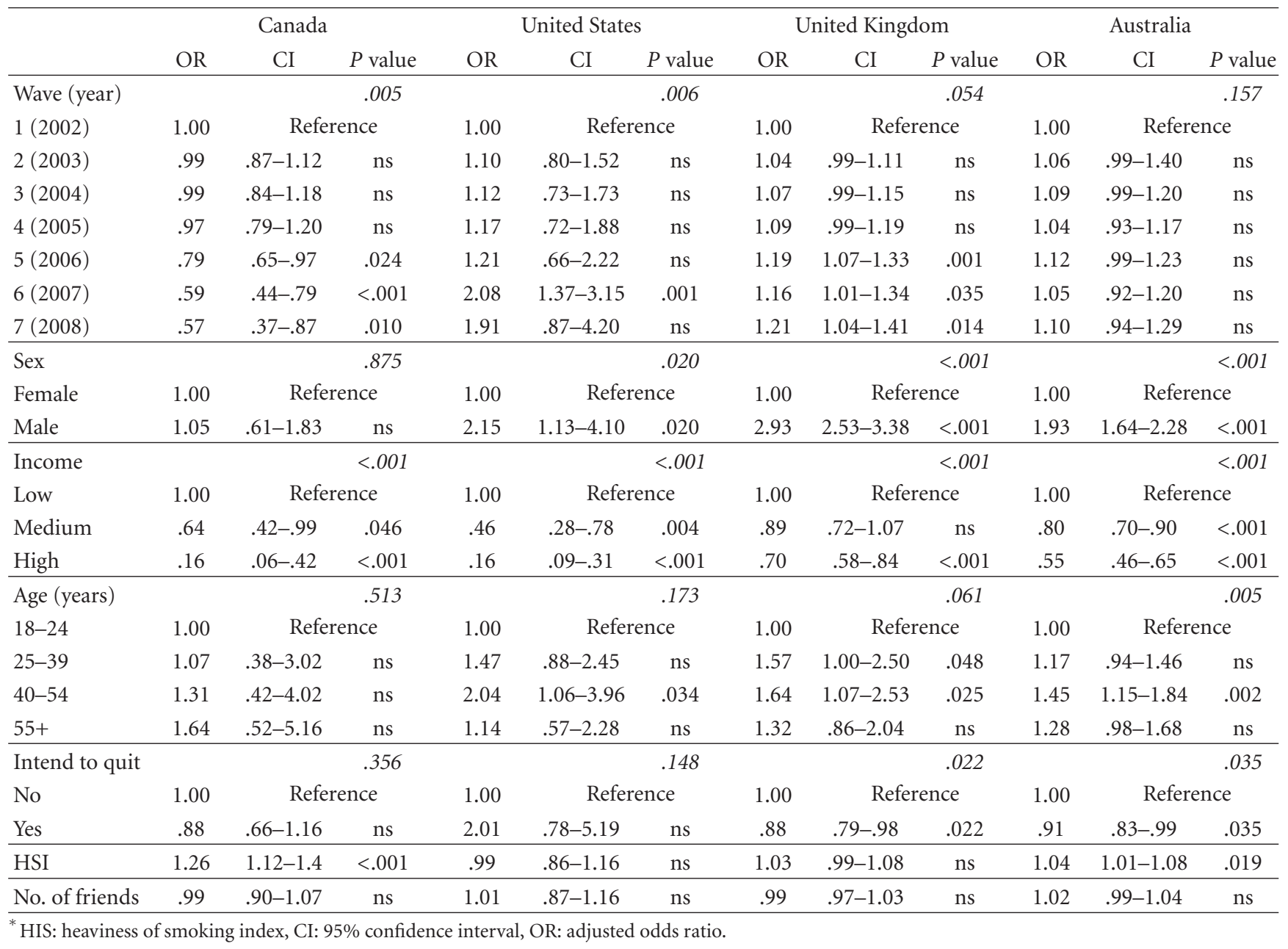

TABLE 3: Self-reported reasons for smoking RYO (all RYO users; Wave 7 in 2008, weighted data, multiple responses allowed).

\begin{tabular}{lcccc}
\hline \multirow{2}{*}{ Reason given } & \multicolumn{3}{c}{ Percentage of respondents } \\
& Canada & US & UK & 95.4 \\
Australia \\
\hline Cheaper than FM & 93.2 & 94.3 & 49.6 & 85.4 \\
Reduce amount smoked* & 46.6 & 52.4 & 62.7 & 53.1 \\
Taste & 41.2 & 42.0 & 63.3 \\
Healthier & 24.5 & 28.3 & 26.9 & 39.6 \\
\hline
\end{tabular}

* More specifically "because they help you reduce the amount smoked."

a significant interaction effect in Australia between age and wave with two clear age segments for sometime use emerging over the seven Waves (18-39 increasing prevalence and 40+ low prevalence).

The relationship with "financial stress" was again tested using data from Waves 4-7. In this case, unlike the situation with respect to predominant use, significant interactions between age group and financial stress $(P=.031)$ and wave and financial stress $(P=.010)$ emerged. Figure 1 shows the interaction between age and financial stress. This effect was independent of country, so we present the combined data.
It is clear from the graph that young (18-24) smokers experiencing financial stress are not only disproportionate sometime RYO users across all four waves, and their level of sometime use has increased from 2005 (Wave 4). While those $55+$ who are experiencing financial stress also show a rise in prevalence from Wave 5, their highest level of prevalence is lower than the lowest level of 18-24 year olds.

3.4. Reasons for Using RYO. The most common reason cited for using RYO (Table 3) was relative cost. From Waves 5 to 7 , believing that RYO cigarettes are healthier increased 


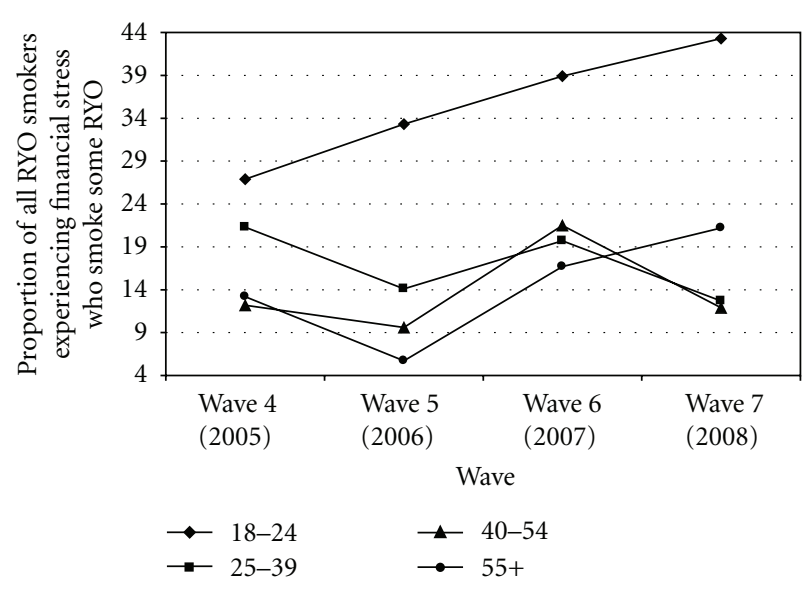

FIGURE 1: Proportion of all RYO users experiencing financial stress who smoke some RYO, by age group (4 country data, 2005-2008).

significantly as a reason for using RYO in Canada $(15.3 \% \rightarrow$ $24.4 \% ; P=.021$ ), but no clear trend emerged in the other three countries. Australian RYO smokers identified health as a reason for smoking RYO more than RYO smokers from other countries. It is noteworthy that while those who predominantly use RYO, and those who are sometime users, give equal weight to saving money and the assumed health advantages, predominant RYO smokers are disproportionately inclined to cite "they taste better" as a reason for smoking RYO compared with sometimes users (64\% versus 35\%).

\section{Discussion}

We found the highest level of any RYO use is in the UK, followed by Australia, Canada and the USA, confirming and extending our earlier findings [3]. Consistent with our hypotheses, any use of RYO is increasing in the UK and probably in the USA, but is falling in Canada. RYO use relative to FM use is changing in quite different ways in the four countries under study, albeit with some core similarities. Understanding such a complex dynamic requires a systemic approach to the issue [25-29] to elucidate the dynamic relationships between countries, economic drivers, cultural norms, tobacco industry strategies, access to alternatives to $\mathrm{RYO}$, tobacco control policies, and other factors.

Predominant use of RYO increased as a proportion of any RYO use in all four countries, most markedly in the USA, and increased as a proportion of total cigarette smoking in the USA and the UK. Compared to sometime RYO users, predominant users were more likely to have low-income, tended to be older, were disproportionately male and far more likely to cite "taste" as a reason for smoking RYO. However, young smokers experiencing financial stress were more likely to be sometime users than predominant users, and this interaction was independent of country.

We analysed the results to establish the extent to which they are consistent with price and financial need being the primary drivers of RYO use. Smokers themselves say that saving money is the main reason for RYO use, as this and other studies have found $[1,3,5]$. Further, use is highest in low income groups, especially predominant use. We assume that the typical pattern is for smokers to start using RYO on an occasional basis and only progress to predominant use if there are sufficient reasons for doing so (e.g., financial stress). Once this happens they begin to espouse different rationales for their RYO use (e.g., taste).

The clearest increases in predominant use were in the USA and UK: the two countries that arguably have been hardest hit by the GFC [14-16]. It is noteworthy that in Waves Six (2007) and Seven (2008), RYO smokers in the USA were more likely than FM smokers to say they were experiencing financial stress. One could speculate that in light of the financial pressures, in the USA smokers may have switched to RYO to reduce expenditure. The high, and increasing, level of UK RYO use reported by other studies $[11,12]$ was replicated. It is clear that RYO is a stable, mainstream market segment in the UK and easy access to duty-free RYO as well as a favourable tax regime [13] makes it relatively easy to reduce tobacco-related expenditure via RYO use.

Even before the GFC, the US industry was forecasting growth in the RYO segment, with cigarette manufacturers moving to take over existing niche manufacturers like Lane and Santa Fe. By 2004 Reynolds/Brown \& Williamson thereby controlled $36 \%$ of the market, with Republic controlling an equivalent proportion [30]. Furthermore, as economic conditions deteriorated, manufacturers introduced tubes with longer filters (saving tobacco), and extra slim rolling papers, filter tips, and rolling machines [31].

The predominant use of RYO in Australia is relatively stable, but is increasing as a proportion of all RYO smoking, with use of sometime RYO falling substantially from Wave One to Wave Seven. The GFC affected Australia less than the USA and the UK and this may be partially responsible for the flat profile of predominant use compared to the clear increases in prevalence observed in the latter two countries.

The pattern of RYO use in Canada was the most distinct. Both predominant and sometime RYO use fell significantly (although sometime use fell proportionally more). The use of cheap contraband FM cigarettes among Canadians, especially the young [18], and the burgeoning share of discounted or cheap brands of cigarettes in that country, which had risen from $2 \%$ of the total market in 2002 to $42.8 \%$ in 2005 [32], are all factors that could help explain the decline. The net prevalence of RYO smokers (relative to FM smokers) saying they have been experiencing financial stress has been falling. It is likely that many of those experiencing substantial financial stress are using contraband tobacco or other lowcost alternatives that are available in Canada.

RYO cigarettes are an effective way of continuing to smoke at lower cost. This results in less revenue to government, made worse when the RYO tobacco is smuggled or otherwise taxed at lower rates. Of particular concern is the likelihood that this low-cost tobacco reduces incentives for smokers to quit. Similarly, there are concerns that RYO smoking might incur greater harm to health [7-9]. All these are good reasons for governments to act to reduce RYO use as part of an overall tobacco control strategy which could also 
include initiatives to support disadvantaged smokers (e.g., augmented programs of smoking cessation assistance and transfer of additional tax revenues to the poorest sectors of society).

Even though the proportion believing that RYO is healthier than FM use is a minority, that any group of smokers should hold such misconceptions is concerning. From a public health perspective, there is no justification for allowing tobacco companies to add "value" to RYO tobacco through messages about it being "natural" and "less harmful."

In light of the prevalence of the health reason, we would argue that RYO smokers (especially the young) should not only be subject to the same health messages as other smokers but in addition, warnings on packaging and elsewhere should also stress that smoking RYO is at least as harmful as smoking FM. However, this needs to be qualified by the observation that peer-group pressure among young people is strong, and where a young peer group regularly uses RYO and reinforces use with myths about relative safety, health messages will need to be carefully framed. Clearly, research with such groups should be a prerequisite as part of adopting such a strategy.

Consideration also needs to be given to raising taxes on RYO to make its cost-point more comparable to FM cigarettes. This has been recommended previously [1] and a differentially higher one-off increase in excise tax on RYO tobacco has been imposed in New Zealand to help to stem rising $\mathrm{RYO}$ usage in that country (i.e., a tax of $24 \%$ on $\mathrm{RYO}$ versus $10 \%$ for FM cigarettes). This went some way toward equalizing RYO and FM cigarettes, but not entirely in terms of cost per cigarette, based on what is known about the weight of RYO cigarettes in NZ [4].

However, price-related interventions need to acknowledge that smokers will try to maximize the amount of nicotine they get from their delivery device, and research is needed to see if smokers respond by smoking their RYO cigarettes harder, something with the potential to increase harms. In considering tax equalization strategies, evidence from the UK that RYO tobacco is easier to smuggle means that such suggestions need to be carefully researched and backed up by increased resources to undermine trafficking of illicit tobacco.

Finally, trying to stop for-profit companies attempting to value-add to their products in search of increased sales is a futile exercise unless well-designed and enforced regulation is used. Governments need to confront the contradiction that allows companies to market products for profit that it is their avowed policy to discourage $[33,34]$ and do this for all forms of smoked tobacco. They should also do so in ways that minimize smuggling and other illicit supply, recognizing that this may be harder to stop for RYO tobacco than for FM cigarettes.

This study has several limitations. First, the relatively small number of RYO smokers in any given wave, especially in the USA, meant that following those smokers who stayed in the sample to monitor their choices of RYO versus FM cigarettes was impractical. In this situation the GEE technique enabled us to monitor aggregate changes in tobacco use and, at the same time, allow for interwave correlation.
Second, it is extremely difficult, if not impossible, to quantify the links between exogenous drivers (e.g., the GFC, access to contraband, state/provincial tax regimes) using regressionbased models like GEE.

\section{Acknowledgments}

The data collection for the ITC project is supported by Grants R01 CA 100362 and P50 CA111236 (Roswell Park Transdisciplinary Tobacco Use Research Center) from the National Cancer Institute of the United States, Robert Wood Johnson Foundation (045734), Canadian Institutes of Health Research (57897), National Health and Medical Research Council of Australia (265903 and 450110), Cancer Research UK (C312/A3726), and Canadian Tobacco Control Research Initiative (014578), with additional support from the Propel Centre for Population Health Impact at the University of Waterloo.

\section{References}

[1] D. Young, N. Wilson, R. Borland, R. Edwards, and D. Weerasekera, "Prevalence, correlates of, and reasons for using rollyour-own tobacco in a high ryo use country: findings from the ITC New zealand survey," Nicotine and Tobacco Research, vol. 12, no. 11, pp. 1089-1098, 2010.

[2] D. Young, H. H. Yong, R. Borland et al., "Prevalence and correlates of roll-your-own smoking in Thailand and Malaysia: findings of the ITC-South East Asia Survey," Nicotine and Tobacco Research, vol. 10, no. 5, pp. 907-915, 2008.

[3] D. Young, R. Borland, D. Hammond et al., "Prevalence and attributes of roll-your-own smokers in the International Tobacco Control (ITC) Four Country Survey," Tobacco Control, vol. 15, no. 3, pp. iii76-iii82, 2006.

[4] M. Laugesen, M. Epton, C. M. Frampton, M. Glover, and R. A. Lea, "Hand-rolled cigarette smoking patterns compared with factory-made cigarette smoking in New Zealand men," BMC Public Health, vol. 9, article no. 194, 2009.

[5] R. J. O'Connor, A. McNeill, R. Borland et al., "Smokers' beliefs about the relative safety of other tobacco products: findings from the ITC Collaboration," Nicotine and Tobacco Research, vol. 9, no. 10, pp. 1033-1042, 2007.

[6] D. Young, G. Fong, R. Borland, K. M. Cummings, and D. Hammond, "Roll-your-own (RYO) cigarettes: prevalence, reasons for use and the use of filters. Findings from the ITC four country survey 2002-06," in Proceedings of the SRNT 14th Annual General Meeting, Portland, Ore, USA, 2008.

[7] A. J. Tuyns and J. Esteve, "Pipe, commercial and handrolled cigarette smoking in oesophageal cancer," International Journal of Epidemiology, vol. 12, no. 1, pp. 110-113, 1983.

[8] E. de Stefani, F. Oreggia, S. Rivero, and L. Fierro, "Hand-rolled cigarette smoking and risk of cancer of the mouth, pharynx, and larynx," Cancer, vol. 70, no. 3, pp. 679-682, 1992.

[9] A. Engeland, T. Haldorsen, A. Andersen, and S. Tretli, "The impact of smoking habits on lung cancer risk: 28 years' observation of 26,000 Norwegian men and women," Cancer Causes and Control, vol. 7, no. 3, pp. 366-376, 1996.

[10] L. Shahab, R. West, and A. McNeill, "A comparison of exposure to carcinogens among roll-your-own and factory-made cigarette smokers," Addiction Biology, vol. 14, no. 3, pp. 315320, 2009. 
[11] G. N. Connolly and H. R. Alpert, "Trends in the use of cigarettes and other tobacco products, 2000-2007," Journal of the American Medical Association, vol. 299, no. 22, pp. 2629-2630, 2008.

[12] S. Robinson and C. Bugler, General Lifestyle Survey: Smoking and Drinking Among Adults, Office for National Statistics, Newport, UK, 2010.

[13] E. Devlin, D. Eadie, and K. Angus, "Rolling tobacco," Report Prepared for the National Health Service, Centre for Tobacco Control Research, University of Strathclyde, Glasgow, UK, 2003.

[14] Government Accountability Office, Information on Recent Default and Foreclosure Trends for Home Mortgages and Associated Economic and Market Developments, GAO-08-78R, http:// www.gao.gov/new.items/d0878r.pdf, 2007.

[15] US Department of Labor, Household Data Annual Averages, Employment and Earning, http://data.bls.gov/pdq/SurveyOutputServlet;jsessionid=035D89EC9CFB509746CF2B32A63E1A19.tc_instance5.

[16] UK Office of National Statistics, Trading Economics, http:// www.tradingeconomics.com/Economics/UnemploymentRate.aspx?Symbol=GBP.

[17] B. King, Think Smoking Rollies Is "Safer"? Think Again, Sydney Morning Herald, Sydney, Australia, 2010.

[18] R. C. Callaghan, S. Veldhuizen, and I. David, "Contraband cigarette consumption among adolescent daily smokers in Ontario, Canada," Tobacco Control, vol. 20, no. 2, pp. 173-174, 2011.

[19] G. T. Fong, K. M. Cummings, R. Borland et al., "The conceptual framework of the International Tobacco Control (ITC) Policy Evaluation Project," Tobacco Control, vol. 15, no. 3, pp. iii3-iii11, 2006.

[20] M. E. Thompson, G. T. Fong, D. Hammond et al., "Methods of the international tobacco control (ITC) four country survey," Tobacco Control, vol. 15, supplement 3, pp. iii12-iii18, 2006.

[21] N. Wilson, Methods report for the New Zealand Arm of the International Tobacco Control Policy Evaluation Survey (ITC Project), Otago University, Wellington, New Zealand, 2009.

[22] H. H. Yong, R. Borland, K. M. Cummings et al., "Impact of the removal of misleading terms on cigarette pack on smokers' beliefs about Light/Mild cigarettes: cross-country comparisons," Addiction, vol. 106, no. 12, pp. 2204-2213, 2011.

[23] M. Siahpush and J. B. Carlin, "Financial stress, smoking cessation and relapse: results from a prospective study of an Australian national sample," Addiction, vol. 101, no. 1, pp. 121127, 2006.

[24] T. F. Heatherton, L. T. Kozlowski, R. C. Frecker, W. Rickert, and J. Robinson, "Measuring the heaviness of smoking: using self-reported time to the first cigarette of the day and numer of cigarettes smoked per day," British Journal of Addiction, vol. 84, no. 7, pp. 791-800, 1989.

[25] R. Borland, D. Young, K. Coghill, and J. Ying Zhang, "The tobacco use management system: analyzing tobacco control from a systems perspective," American Journal of Public Health, vol. 100, no. 7, pp. 1229-1236, 2010.

[26] D. Young, R. Borland, and K. Coghill, "An actor-network theory analysis of policy innovation for smoke-free places: understanding change in complex systems," American Journal of Public Health, vol. 100, no. 7, pp. 1208-1217, 2010.

[27] National Cancer Institute, "Greater than the sum: systems thinking in tobacco control, Ch. 3, systems thinking: potential to transform tobacco control," NCI Tobacco Control Monograph 18, U.S. Department of Health and Human Services,
National Institutes of Health, National Cancer Institute, Bethesda, Md, USA, 2007.

[28] S. J. Leischow and B. Milstein, "Systems thinking and modeling for public health practice," American Journal of Public Health, vol. 96, no. 3, pp. 403-405, 2006.

[29] K. McLeroy, “Thinking of systems," American Journal of Public Health, vol. 96, no. 3, p. 402, 2006.

[30] B. Brinson, "The make-your-own segment is booming in the US,” Tech. Rep., Tobacco Reporter, Raleigh, NC, USA, 2004.

[31] Tobacco Reporter Editorial Staff, "Do it yourself: a look at key players in the RYO and MYO business," Tech. Rep., Tobacco Reporter, Raleigh, NC, USA, 2009.

[32] A. Diener, R. Ahmed, M. Kaiserman, and M. Farnworth, "Examining the effects of tax increases on discount and premium cigarettes in Canada, 2001-2005," in Proceedings of the 6th World Congress: Explorations in Health, Copenhagen, Denmark, 2007.

[33] R. Borland, "A strategy for controlling the marketing of tobacco products: a regulated market model," Tobacco Control, vol. 12, no. 4, pp. 374-382, 2003.

[34] C. Callard, D. Thompson, and N. Collishaw, "Transforming the tobacco market: why the supply of cigarettes should be transferred from for-profit corporations to non-profit enterprises with a public health mandate," Tobacco Control, vol. 14, no. 4, pp. 278-283, 2005. 


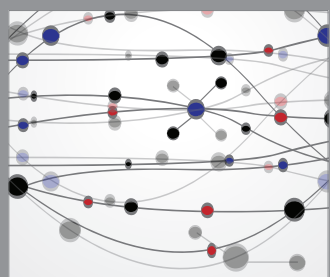

The Scientific World Journal
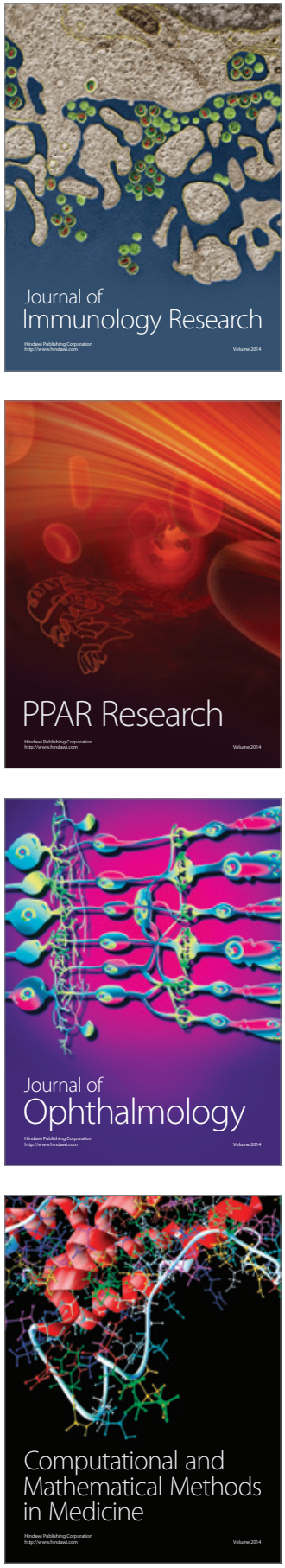

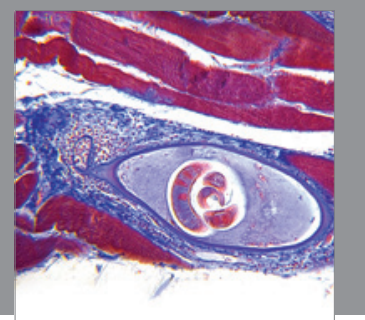

Gastroenterology

Research and Practice
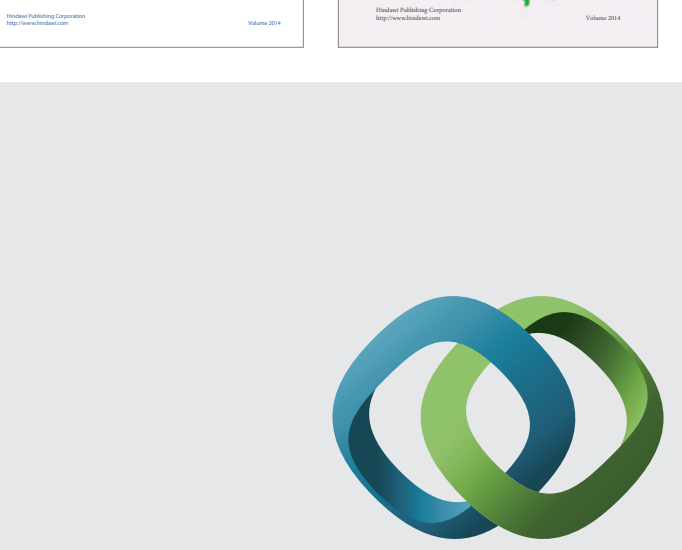

\section{Hindawi}

Submit your manuscripts at

http://www.hindawi.com
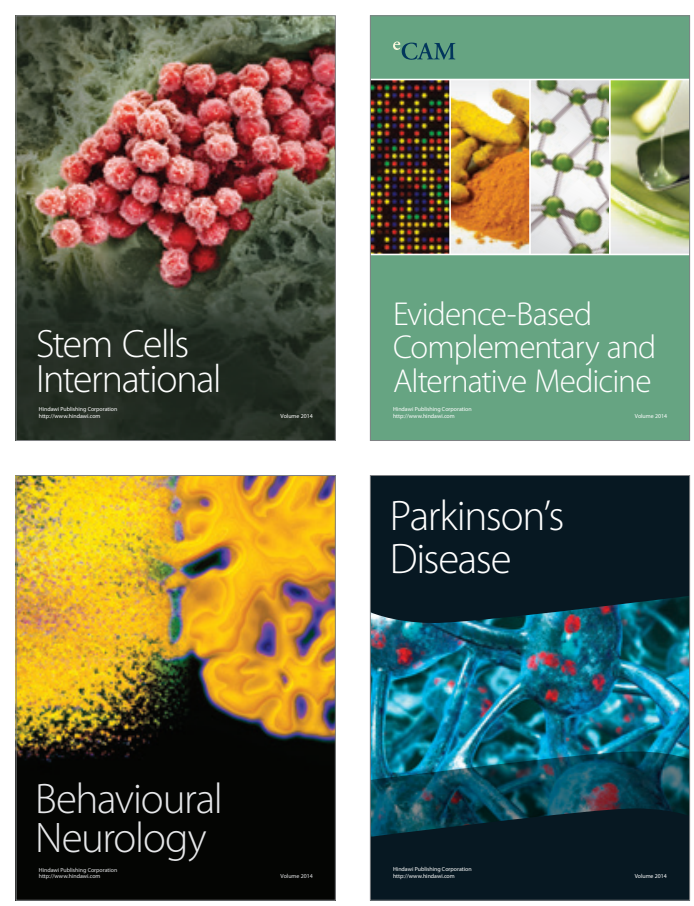

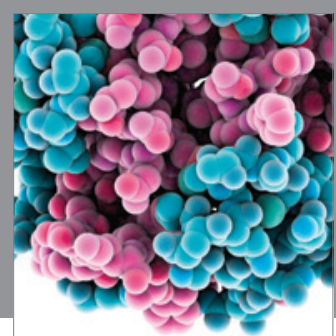

Journal of
Diabetes Research

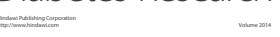

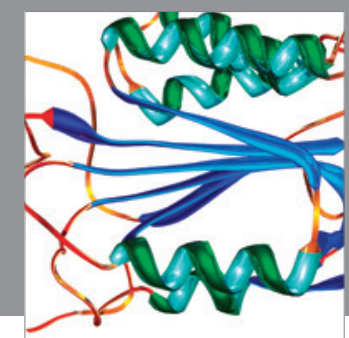

Disease Markers
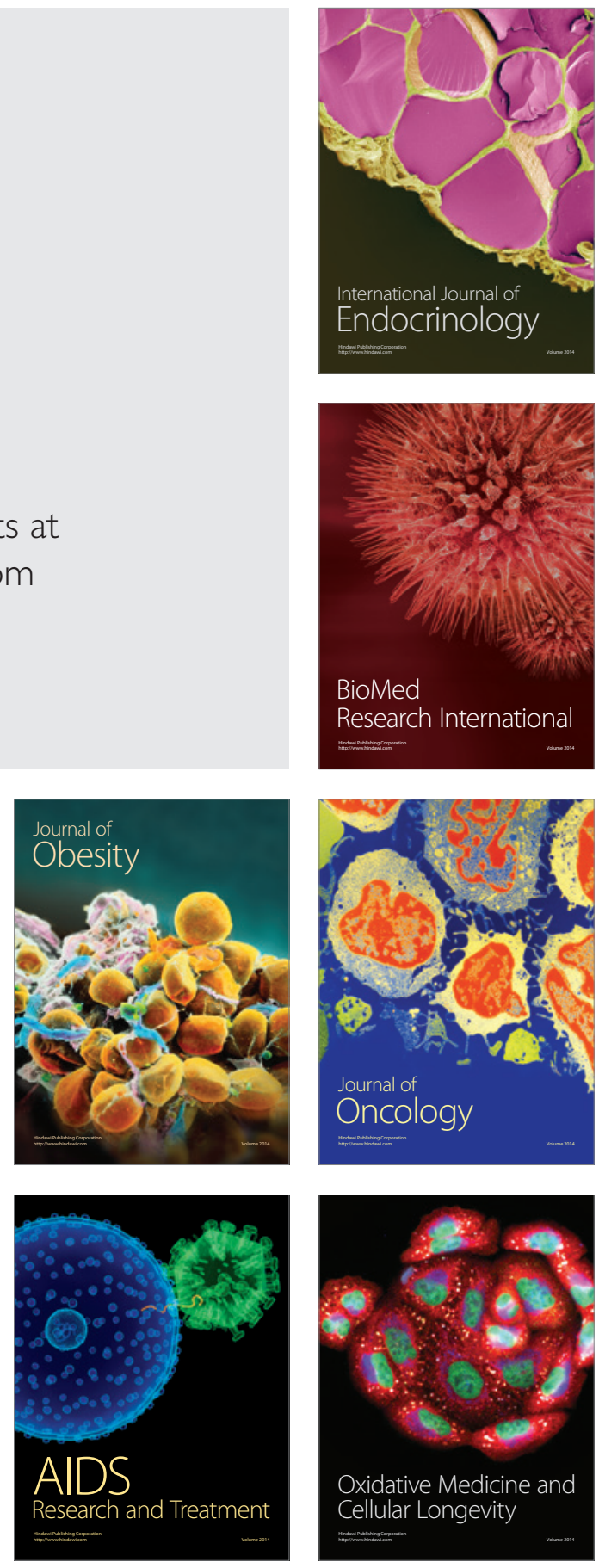